$67-74$

\title{
Addressing the challenges and controversies of managing os odontoideum: results of a systematic review
}

\author{
Authors Jefferson R Wilson ${ }^{1}$, Joseph R Dettori ${ }^{2}$, Ellen M VanAlstyne ${ }^{2}$, Michael G Fehlings ${ }^{1}$ \\ Institutions $\quad{ }^{1}$ Division of Neurosurgery, University of Toronto, Toronto, Ontario, Canada \\ ${ }^{2}$ Spectrum Research, Tacoma, Washington, USA
}

\section{ABSTRACT}

Introduction: Os odontoideum is a rare condition with a controversial pathogenesis and poorly understood natural history. As a result, it is difficult for clinicians to predict which patients require surgical fusion to prevent symptomatic progression and potentially devastating neurologic injury.

Methods: We undertook a systematic review of the literature to evaluate the clinical outcomes in the treatment of asymptomatic and symptomatic cases of os odontoideum. Pubmed, EMBASE, Cochrane, National Guideline Clearinghouse Databases as well as bibliographies of key articles were searched. Articles were reviewed by two independently working reviewers. Inclusion and exclusion criteria were set and each article was subject to a predefined quality rating scheme.

Results: We identified eleven articles meeting our inclusion criteria. Seven studies included patients with asymptomatic os odontoideum discovered incidentally from which it was possible to examine data on 18 individuals. Six studies were identified containing more than 15 patients with symptomatic os odontoideum.

Conclusion: The existing literature regarding both asymptomatic or symptomatic os odontoideum and its treatment is very limited. No definitive conclusions can be drawn from these studies. A basic approach to the management of os odontoideum is offered based on the findings of this study. 


\section{STUDY RATIONALE AND CONTEXT}

Os odontoideum is a rare condition defined radiographically as an ossicle with smooth circumferential cortical margins representing the odontoid process that has no osseous continuity with the body of $\mathrm{C} 2$. It may be classified as stable or unstable based on the extent of excursion of the atlas from the axis on dynamic imaging [1]. The pathogenesis of this lesion remains controversial with arguments for both acquired and congenital causes postulated in the literature. At present, however, most authors believe that it results from a previous trauma leading to a chronic nonunion fracture of the odontoid process [2-5].

Although os odontoideum has a clear radiographic definition, its clinical manifestations are variable with patients existing on a spectrum of symptom severity from completely asymptomatic or with neck pain to severe spinal cord injury. Due to the paucity of cases and the poorly understood natural history of this condition it is difficult for clinicians to predict which patients require surgical fusion to prevent symptomatic progression and potentially devastating neurologic injury.

In order to review the collective experience and to help augment our current understanding of this condition we have undertaken a systematic review of the literature to evaluate the clinical outcomes in the treatment of asymptomatic and symptomatic cases of os odontoideum.

\section{MATERIALS AND METHODS}

Study design: Systematic review.

\section{Sampling:}

- Search: Pubmed, EMBASE, Cochrane, and National Guideline Clearinghouse Databases; bibliographies of key articles

- Dates searched: 1970 to August 2009.

- Inclusion criteria

Asymptomatic: case reports, case series of any size, adults and children

Symptomatic: case series that included 15 or more patients, adults and children

- Outcomes: fusion (\%), relief of symptoms

- Analysis: descriptive statistics

Details about methods can be found in the web appendix at www.aospine.org/ebsj.

\section{RESULTS}

We identified eleven articles meeting our inclusion criteria (Fig 1). Seven studies included patients with asymptomatic os odontoideum discovered incidentally from which it was possible to examine data on 18 individuals [3, 4, 6-10]. Six studies were identified containing more than 15 patients with symptomatic os odontoideum [2, $3,5,10-12]$.

\section{Asymptomatic incidental os odontoideum}

- Eighteen individual asymptomatic patients were identified, for which the demographics, treatment, and outcomes are shown in Table 1 [3, 4, 6-10].

- Among the eleven patients for which demographic data were supplied, $64 \%$ were pediatric, and $64 \%$ were male. Three had Klippel-Feil syndrome, two had Down's syndrome, and one had ectodermal dysplasia.

- Follow-up time was reported in only seven of the patients and ranged from $1.4-11$ years.

- Nine patients were treated with spinal fusion procedures to stabilize $\mathrm{Cl}$ and $\mathrm{C} 2$, and in these cases, solid fusion was achieved. These patients continued to be asymptomatic, although one paper pointed out that the neck range of motion was reduced secondary to fusion.

- Nine patients were treated conservatively, and these were reported to remain stable with no symptomatolgy attributable to their os odontoideum having developed over the course of follow-up. One patient died from pulmonary cancer at 11-years follow-up, but his spinal condition remained stable until that time. 


\section{Symptomatic os odontoideum}

- Three-hundred-and-forty-four patients in six studies with symptomatic os odontoideum are summarized with respect to demographics, treatment, and outcomes, Table 2 [2, 3, 5, 10-12]. Ages ranged from 3-73 years and $62 \%$ were males. Forty-seven patients had a preexisting diagnosis including KlippelFeil syndrome, Down's syndrome, dysplasia, occipitalization, hypertrophy of the anterior atlantal arch, basilar impression, spondyloepiphyseal dysplasia, metatrophic dwarfism, or Morquio's syndrome. All but 19 patients underwent cervical fusion.

- Fusion rate

The rate of fusion reported in four studies was $99 \%$ $(214 / 216)[5,10-12]$.

- Symptoms

Three case series report on the change in symptoms following spinal fusion. After fusion, symptoms were completely resolved or significantly reduced in all patients $(n=39)$ in one study [10], and completely resolved in $88 \%$ in another [2]. Klimo et al reported that symptoms resolved in $68 \%$ of patients with pain and $39 \%$ with neuropathy $(20 \%$ with myelopathy and $100 \%$ with intermittent neuropathy) [5]. It is unclear how many different patients this represents of the total study population as patients may have more than one symptom. No case series reported worse symptoms or neurological status following treatment.
In the one retrospective cohort study, patients were grouped by cord sign status and treatment mode [3]. In patients with no cord signs, symptoms resolved in $50 \%$ of those patients who were treated conservatively and only $11 \%$ of those treated with surgery. In patients with cord signs, $25 \%$ of patients were symptom free whether they received conservative or operative treatment (Fig 2).

\section{CLINICAL GUIDELINES}

In 2001, the American Association of Neurological Surgeons and the Congress of Neurological Surgeons (AANS/CNS) provided evidence-based clinical recommendations for the treatment of os odontoideum [1].

- No clinical evidence was found supporting the recommendation of operative treatment standards or guidelines for os odontoideum.

- For asymptomatic patients, clinical and radiographic surveillance may be the appropriate management.

- Patients with neurological symptoms/signs and Cl-2 instability are generally managed with posterior fixation and fusion.

- Other operative measures may be warranted in cases of irreducible cervicomedullary compression and/or occipitocervical instability.

- The paucity of high quality studies was noted.

\section{Fig 1 Flow chart showing results of literature search}

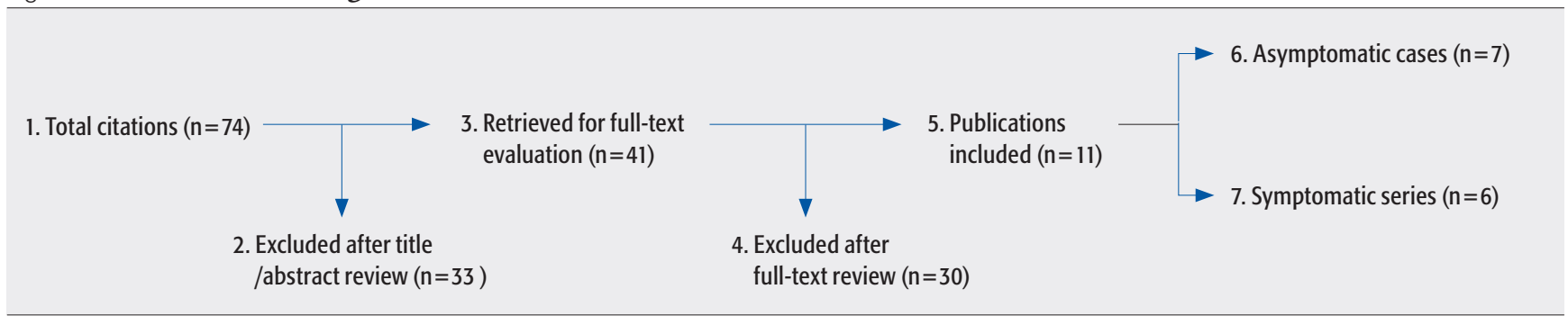

Fig 2 Symptom status of patients without and with cord signs after surgical or nonsurgical treatment of symptomatic os odontoideum [3]

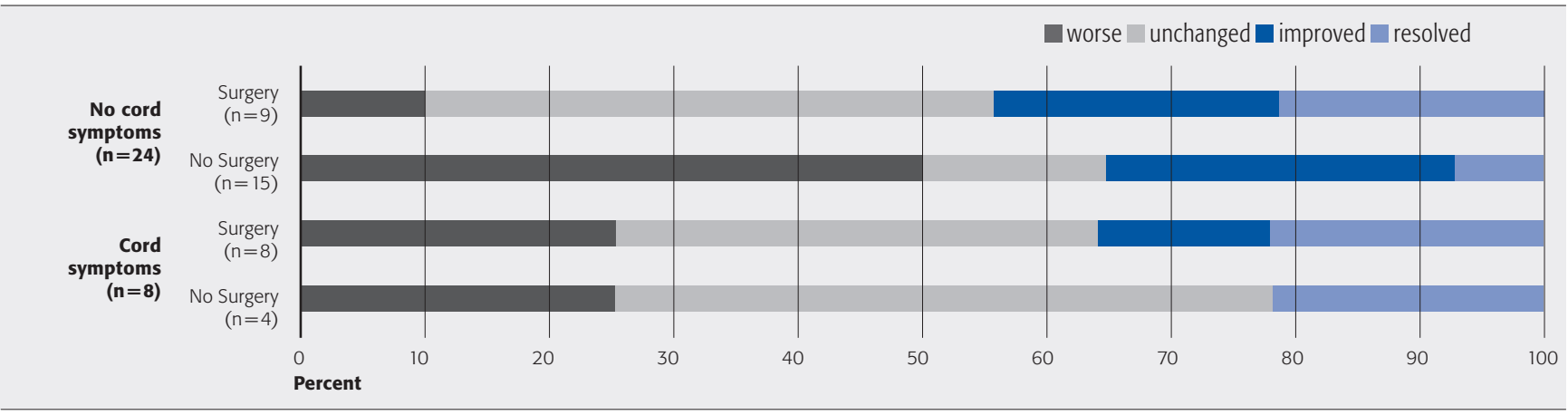




\begin{tabular}{|c|c|c|c|c|c|c|c|c|}
\hline $\begin{array}{l}\text { Patient } \\
\text { no. }\end{array}$ & Author & $\begin{array}{c}\text { Age } \\
\text { (years) }\end{array}$ & Sex & $\begin{array}{l}\text { Preexisting } \\
\text { diagnosis }\end{array}$ & Instability & $\begin{array}{l}\text { operative } \\
\text { fusion }\end{array}$ & $\begin{array}{l}\text { Follow-up } \\
\text { (years) }\end{array}$ & Results \\
\hline 1 & Dai* & $\mathrm{nr}$ & $\mathrm{nr}$ & $\mathrm{nr}$ & $\mathrm{nr}$ & no & $\mathrm{nr}$ & - Remained stable \\
\hline 2 & Dai* & $\mathrm{nr}$ & $\mathrm{nr}$ & $\mathrm{nr}$ & $\mathrm{nr}$ & no & $\mathrm{nr}$ & - Remained stable \\
\hline 3 & Dai* & $\mathrm{nr}$ & $\mathrm{nr}$ & $\mathrm{nr}$ & $\mathrm{nr}$ & no & $\mathrm{nr}$ & - Remained stable \\
\hline 4 & Dai* & $\mathrm{nr}$ & $\mathrm{nr}$ & $\mathrm{nr}$ & $\mathrm{nr}$ & no & $\mathrm{nr}$ & - Remained stable \\
\hline 5 & Dai* & $\mathrm{nr}$ & $\mathrm{nr}$ & $\mathrm{nr}$ & $\mathrm{nr}$ & no & $\mathrm{nr}$ & - Remained stable \\
\hline 6 & Dai* & $\mathrm{nr}$ & $\mathrm{nr}$ & $\mathrm{nr}$ & $\mathrm{nr}$ & yes & $\mathrm{nr}$ & - Solid arthrodesis achieved \\
\hline 7 & Dai* & $\mathrm{nr}$ & $\mathrm{nr}$ & $\mathrm{nr}$ & $\mathrm{nr}$ & yes & $\mathrm{nr}$ & - Solid arthrodesis achieved \\
\hline 8 & Forlin & 8 & $\mathrm{~F}$ & Down's syndrome & yes & yes & 5 & $\begin{array}{l}\text { - Postoperative pin track infection } \\
\text { resolved after halo removal } \\
\text { - Partial resorption of the fusion mass } \\
\text { treated by regrafting at } 3 \text { months } \\
\text { - Asymptomatic }\end{array}$ \\
\hline 9 & Forlin & 9 & M & Down's syndrome & yes & yes & 2 & -Asymptomatic \\
\hline 10 & Hickam & 9 & $\mathrm{~F}$ & none & no & yes & $\mathrm{nr}$ & $\begin{array}{l}\text {-Asymptomatic } \\
\text { - Decrease in rotation of head }\end{array}$ \\
\hline 11 & Juhlt & 9 & M & $\mathrm{nr}$ & yes & yes & $\mathrm{nr}$ & $\begin{array}{l}\text { - Extension } 75^{\circ} \text {, lateral flexion right } 0^{\circ} \\
\text { and left } 30^{\circ} \text {, rotation right } 30^{\circ} \text { and left } 45^{\circ}\end{array}$ \\
\hline 12 & Juhlt & 44 & M & $\mathrm{nr}$ & no & no & $11 \dagger$ & - Asymptomatic \\
\hline 13 & Morgan & 39 & M & Klippel-Feil & no & no & $\mathrm{nr}$ & - Asymptomatic \\
\hline 14 & Morgan & 64 & $\mathrm{~F}$ & Klippel-Feil & no & no & $\mathrm{nr}$ & - Asymptomatic \\
\hline 15 & Sankar & 13 & M & None & yes & yes & 1.4 & - Fusion achieved at 1.9 months \\
\hline 16 & Sankar & 12 & M & $\begin{array}{l}\text { Ectodermal } \\
\text { dysplasia }\end{array}$ & yes & yes & 2.8 & - Fusion achieved at 5.9 months \\
\hline 17 & Sankar & 2 & $\mathrm{~F}$ & Klippel-Feil & yes & yes & 2.2 & - Fusion achieved at 12.9 months \\
\hline 18 & Spierings & 28 & M & None & no & no & 9 & -Asymptomatic \\
\hline
\end{tabular}

$\mathrm{nr}=$ not reported; Klippel-Feil type fusion of $\mathrm{C} 2$ and $\mathrm{C} 3$.

* Dai: mean age 24.6 and age range 7-56 years, and follow-up of 6.5 years (1-16) are reported for the total number of asymptomatic and symptomatic patients, $\mathrm{N}=44$.

$\dagger$ Juhl: patient died of pulmonary cancer 11 years after diagnosis of os odontoideum. 
Table 2 Symptomatic patients treated either nonoperatively or operatively for os odontoideum and their results

\begin{tabular}{|c|c|c|c|c|c|c|c|c|c|}
\hline Author & $\mathbf{N}$ & $\begin{array}{l}\text { Mean } \\
\text { age } \\
\text { (range) in } \\
\text { years }\end{array}$ & $\begin{array}{c}\% \\
\text { male }\end{array}$ & $\begin{array}{l}\text { Preexisting } \\
\text { diagnosis }\end{array}$ & Symptoms & $\begin{array}{l}\text { Insta- } \\
\text { bility }\end{array}$ & $\begin{array}{l}\text { Operative } \\
\text { treatment }\end{array}$ & $\begin{array}{l}\text { Mean } \\
\text { follow-up } \\
\text { (range) } \\
\text { in years }\end{array}$ & Results \\
\hline Dai & 39 & $\begin{array}{c}25 \\
(7-56)\end{array}$ & $75 \% *$ & $\begin{array}{l}n=18 \\
\text { - Klippel-Feil }(n=4) \\
\text { - occipitalization }(n=6) \\
\text { - Hypertrophy anterior } \\
\text { atlantal arch }(n=5) \\
\text { - Basilar invagination } \\
(n=2) \\
\text { - Basilar impression } \\
(n=1)\end{array}$ & $\begin{array}{l}\text { Local symptoms: } \\
\text { - cervical pain and/or stiffness }(n=33) \\
\text { - weakness of neck }(n=21) \\
\text { - dizziness }(n=7) \\
\text { - torticollis }(n=9) \\
\text { Neurological findings }(n=30) \text { : } \\
\text { - transient }(n=7) \\
\text { - immediate, nontransient }(n=4) \\
\text { - late-onset progressive }(n=19) \\
\text { - myelopathy }(n=6) \\
\text { - radiculopathy }(n=2) \\
\text { - myelopathy \& radiculopathy }(n=22) \\
\text { - cranial nerve defects }(n=8)\end{array}$ & $95 \%$ & yes & $\begin{array}{c}6.5 \\
(1-16)\end{array}$ & $\begin{array}{l}\text { Fusion: } 100 \% \\
\text { All symptoms } \\
\text { - resolved: } 67 \% \\
\text { - improved: } 33 \%\end{array}$ \\
\hline Fielding & 35 & $\begin{array}{c}19 \\
(3-65)\end{array}$ & $60 \%$ & $\begin{array}{l}\text { - Down's syndrome }(n=1) \\
\text { - Klippel-Feil }(n=1) \\
\text { - Dysplasia }(n=4)\end{array}$ & $\begin{array}{l}\text { - Pain }(n=16) \\
\text { - Neurological }(n=17) \\
\text { - Other }(n=14)\end{array}$ & $100 \%$ & yes & $\begin{array}{c}3.4 \\
(1-10)\end{array}$ & $\begin{array}{l}\text { All symptoms } \\
\text { - resolved: } 88 \% \\
\text { - worse: } 0 \%\end{array}$ \\
\hline Gluf & 22 & $\begin{array}{c}10 \\
(4-16) \\
\end{array}$ & $66 \% \dagger$ & ns & Not described & $100 \%$ & yes & $\begin{array}{c}2.8 \\
(0.25-8.9) \\
\end{array}$ & Fusion: 100\% \\
\hline Klimo & 78 & $\begin{array}{c}21 \\
(1.5-73)\end{array}$ & $62 \%$ & $\begin{array}{l}n=5 \\
\text { - Down's syndrome }(n=3) \\
\text { - Spondyloepiphyseal } \\
\text { dysplasia }(n=1) \\
\text { - Metatrophic dwarfism } \\
(n=1)\end{array}$ & $\begin{array}{l}\text { - Pain }(n=50) \\
\text { - Myelopathy }(n=18) \\
\text { - Intermittent neuropathy }(n=15)\end{array}$ & $\begin{array}{c}\text { 77\% } \\
\text { ant: } 70 \% \\
\text { post: } 10 \% \\
\text { A-P: } 13 \%\end{array}$ & yes & $\begin{array}{c}1.2 \\
(0.1-9.6)\end{array}$ & $\begin{array}{l}\text { Fusion: 100\% } \\
\text { Pain } \\
\text { - resolved: } 68 \% \\
\text { - improved: } 20 \% \\
\text { - unchanged: } 12 \% \\
\text { Neuropathy } \\
\text { - resolved: } 39 \% \\
\text { - improved: } 50 \% \\
\text { - unchanged: } 11 \% \\
\end{array}$ \\
\hline Menezes & 134 & $4-58$ & $55 \%$ & $\begin{array}{l}\text { - Morquio's }(n=2) \\
\text { - Down's syndrome } \\
\text { ( } n=10) \ddagger\end{array}$ & $\begin{array}{l}\text { - Acute neurological deterioration } \\
\text { following trauma }(n=63) \\
\text { - Symptoms insidious }(n=71)\end{array}$ & yes & yes & ns & $\begin{array}{l}\text { Fusion: } 98.5 \% \\
\text {-2nd fusion required } \\
\text { to extend initial } \\
\text { C1-C2 fusion }(n=16)\end{array}$ \\
\hline \multirow[t]{4}{*}{ Spierings } & \multirow[t]{4}{*}{36} & \multirow{4}{*}{$\begin{array}{c}38 \\
(6-62)\end{array}$} & \multirow[t]{4}{*}{$78 \%$} & \multirow{4}{*}{$\begin{array}{l}\text { - Down's syndrome } \\
\qquad(n=1)\end{array}$} & Group A: no cord symptoms $(n=15)$ & $\mathrm{nr}$ & no & \multirow{4}{*}{$\begin{array}{c}8 \\
(0.5-18)\end{array}$} & \multirow{4}{*}{$\begin{array}{l}\text { All symptoms resolved } \\
\text { - Gp A: } 50 \% \\
\text { - Gp B: } 11 \% \\
\text { - Gp C: } 25 \% \\
\text { - Gp D: } 25 \% \\
\text { improved: } \\
\text { - Gp A:14\% } \\
\text { - Gp B: } 45 \% \\
\text { - Gp C: } 50 \% \\
\text { - Gp D: } 37 \% \\
\text { unchanged: } \\
\text { - Gp A: } 29 \% \\
\text { - Gp B: } 22 \% \\
\text { - Gp C: } 0 \% \\
\text { - Gp D: } 13 \% \\
\text { worse: } \\
\text { - Gp A: } 7 \% \\
\text { - Gp B: } 22 \% \\
\text { - Gp C: } 25 \% \\
\text { - Gp D: } 25 \%\end{array}$} \\
\hline & & & & & Group B: no cord symptoms $(n=9)$ & $\mathrm{nr}$ & yes & & \\
\hline & & & & & Group C: cord symptoms $(n=4)$ & $\mathrm{nr}$ & no & & \\
\hline & & & & & Group D: cord symptoms $(n=8)$ & $\mathrm{nr}$ & yes & & \\
\hline
\end{tabular}

$\mathrm{nr}=$ not reported.

* Dai: \% male includes asymptomatic and symptomatic patients.

† Gluf reports \% male for a study population of 45 patients with other diagnoses and 22 os odontoideum patients.

‡ Menezes: possibly other patients have preexisting diagnoses; these 12 patients are specifically listed as among those with reducible lesions but worsening extension. 
EVIDENCE SUMMARY

Question 1: Outcomes of treatment in patients with incidental asymptomatic os odontoideum

\begin{tabular}{ll|l|l|l}
\hline Outcomes & Strength of evidence & Conclusions/comments \\
\hline 1. Symptoms & Very low & Moderate & $\begin{array}{c}\text { - Patients continued to be symptom free with } \\
\text { or without fusion procedure. } \\
\text { - The fusion procedure limits neck range of motion, } \\
\text { but other detrimental effects were not noted. }\end{array}$ \\
\hline 2. Fusion success
\end{tabular}

Details about the determination of strength of evidence can be found in the web appendix at www.aospine.org/ebsj

\begin{tabular}{ll|l|l|l|l}
\hline Question 2: Outcomes of treatment in patients with symptomatic os odontoideum \\
\hline Outcomes & Strength of evidence & Conclusions/comments \\
\hline 1. Symptoms & Very low & Moderate & $\begin{array}{c}\text {-Symptoms were relieved in the majority } \\
\text { of cases after fusion. } \\
\text { - Symptoms were also seen to improve in the } \\
\text { majority of nonoperative patients. }\end{array}$ \\
\hline
\end{tabular}

Details about the determination of strength of evidence can be found in the web appendix at www.aospine.org/ebsj

\section{Illustrative case}

- A 24-year-old woman presents with a history of chronic neck pain, worse in the last 2 months, and a cervical spine $\mathrm{x}$-ray demonstrating os-odontoideum (Fig 3) with $7 \mathrm{~mm}$ of excursion of the atlas from the axis between flexion and extension. Physical examination revealed evidence of myelopathy including brisk deep tendon reflexes, as well as positive Hoffman and Babinski signs bilaterally. MRI performed shortly after presentation was concerning for increased $\mathrm{T} 2$ signal in the upper cervical spinal cord (Fig 4). The patient underwent $\mathrm{Cl} / 2$ posterior screw-rod fixation, with iliac crest bone graft which was fixed in situ with $\mathrm{Cl}-2$ cable cerclage fixation. At 6-months postoperatively, she had experienced complete resolution of her neck pain symptoms and has achieved a solid posterior fusion on x-ray (Fig 5). The patient remains well at 2-year follow-up.

\section{Discussion}

- In 18 case reports, we found no cases of patients with incidental asymptomatic os odontoideum who later developed symptoms whether treated conservatively or surgically. Among symptomatic patients, fusion was the treatment of choice resulting in successful arthrodesis in $99 \%$ of the cases. One retrospective cohort study suggests that the outcome from surgery may not be better than the outcome of conservative care.

- Although the etiology of os odontoideum remains unclear, there are two plausible theories which may account for two different forms of this lesion: 1) it represents a congenital aplastic lesion, 2) it is an acquired entity related to a chronic non-union from a previous traumatic event. For the purposes of this study it is difficult to distinguish between these two subpopulations and hence to draw any conclusions about differences in natural history between them. The existing literature regarding either asymptomatic or symptomatic os odontoideum and its treatment is very limited with only case reports, case series and one retrospective cohort study available for analysis. No definitive conclusions can be drawn from these studies. Further comparative studies with more patients would be necessary to address the question of the benefit of surgery relative to the severity of the symptoms. 
- For asymptomatic patients, posterior $\mathrm{Cl} / 2$ fixation and fusion has been shown to be a safe procedure, however there is no convincing evidence to support its use over conservative therapy. The pros and cons of operative versus nonoperative management need to weighed by the clinician and discussed with the patient.

- For symptomatic patients (severe neck pain, occipital neuralgia or neurological dysfunction), surgical treatment is generally recommended. In these cases, posterior $\mathrm{Cl} / 2$ fixation and fusion is a safe and effective procedure that leads to improvement or stabilization of symptoms in the majority of patients.

\section{Fig 3 Preoperative lateral C-spine x-ray demonstrat- ing os odontoideum}

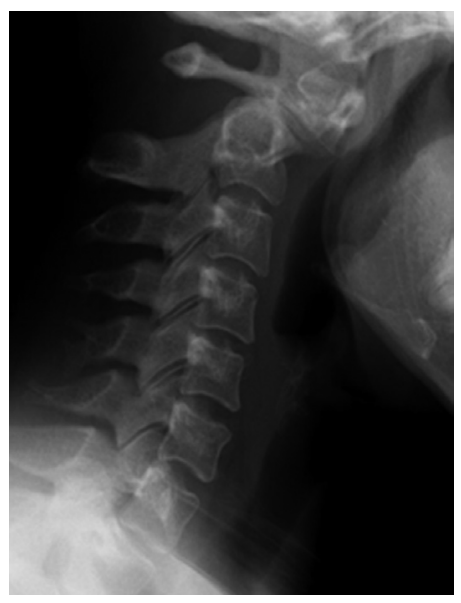

Fig 4 Sagittal T2 MRI demonstrating increased signal in the upper cervical spinal cord at the level of the os odontoideum.

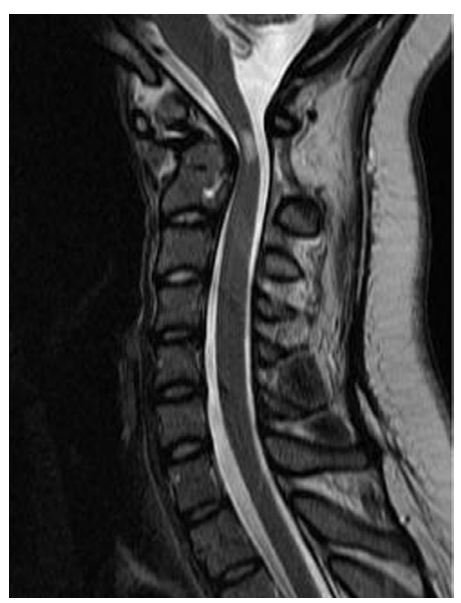

Fig 5 Lateral C-spine $\mathbf{x}$-ray $\mathbf{2}$-years postoperatively posterior $\mathrm{Cl} / 2$ fusion

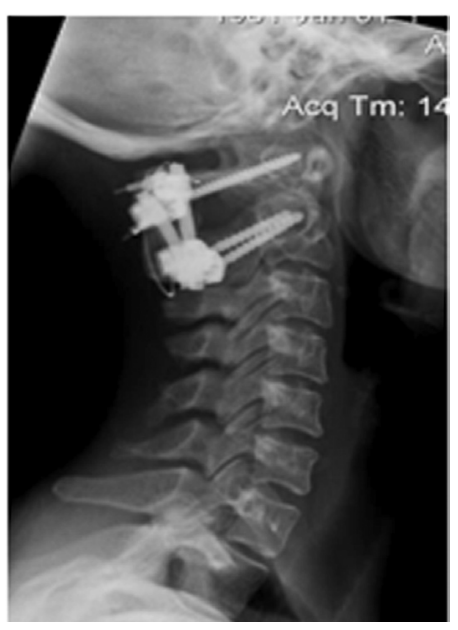




\section{REFERENCES}

1. The Section on Disorders of the Spine and Peripheral Nerves of the American Association of Neurological Surgeons and the Congress of Neurological Surgeons (2001) Os Odontoideum. SpineUniverse Web site. http://www. spineuniverse.com/pdf/traumaguide/19.pdf. Accessed August 15, 2009.

2. Fielding JW, Hensinger RN, Hawkins RJ (1980) Os Odontoideum. J Bone Joint Surg Am; 62:376-383.

3. Spierings EL, Braakman R (1982) The management of os odontoideum. Analysis of 37 cases. J Bone Joint Surg Br; 64:422-428.

4. Sankar WN, Wills BP, Dormans JP, et al (2006) Os odontoideum revisited: the case for a multifactorial etiology. Spine (Phila Pa 1976); 31:979-984.

5. Klimo P, Jr., Kan P, Rao G, et al (2008) Os odontoideum: presentation, diagnosis, and treatment in a series of 78 patients. J Neurosurg Spine; 9:332-342.

6. Juhl M, Seerup KK (1983) Os odontoideum. A cause of atlanto-axial instability. Acta Orthop Scand; 54:113-118.

7. Morgan MK, Onofrio BM, Bender CE (1989) Familial os odontoideum. Case report. J Neurosurg; 70:636-639.

8. Hickam HE, Morrissy RT (1990) Os odontoideum detected on a lateral cephalogram of a 9-year-old orthodontic patient. Am J Orthod Dentofacial Orthop; 98: 89-93.

9. Forlin E, Herscovici D, Bowen JR (1992) Understanding the os odontoideum. Orthop Rev; 21:1441-1447.

10. Dai L, Yuan W, Ni B, et al (2000) Os odontoideum: etiology, diagnosis, and management. Surg Neurol; 53: 106-108.

11. Menezes AH (1999) Pathogenesis, dynamics, and management of os odontoideum. Neurosurg Focus; 6:e2.

12. Gluf WM, Brockmeyer DL (2005) Atlantoaxial transarticular screw fixation: a review of surgical indications, fusion rate, complications, and lessons learned in 67 pediatric patients. J Neurosurg Spine; 2:164-169. 